\title{
Optimal swimming speeds reflect preferred swimming speeds of brook charr (Salvelinus fontinalis Mitchill, 1874)
}

\author{
Christian Tudorache $\cdot$ Robyn A. O'Keefe • \\ Tillmann J. Benfey
}

Received: 25 November 2010/Accepted: 13 December 2010/Published online: 11 May 2011

(C) The Author(s) 2011. This article is published with open access at Springerlink.com

\begin{abstract}
Several measures have been developed to quantify swimming performance to understand various aspects of ecology and behaviour, as well as to help design functional applications for fishways and aquaculture. One of those measures, the optimal swimming speed, is the speed at which the cost of transport (COT) is minimal, where COT is defined as the cost of moving unit mass over unit distance. The experimental protocol to determine the optimal swimming speed involves forced-swimming in a flume or respirometer. In this study, a 4.5-m-long tilted raceway with gradually increasing upstream water speed is used to determine a novel, behaviourally based swimming parameter: the preferred swimming speed. The optimal swimming speed and the preferred swimming speed of brook charr were determined and a comparison of the two reveals that the optimal swimming speed $\left(25.9 \pm 4.5 \mathrm{~cm} \mathrm{~s}^{-1}\right.$ or $1.02 \pm 0.47 \mathrm{bl} \mathrm{s}^{-1}$ ) reflected the preferred swimming speed (between $20 \mathrm{~cm} \mathrm{~s}^{-1}$ or $0.78 \pm 0.02 \mathrm{bl} \mathrm{s}^{-1}$ and $25 \mathrm{~cm} \mathrm{~s}^{-1}$ or $0.95 \pm 0.03 \mathrm{bl} \mathrm{s}^{-1}$ ). The preferred
\end{abstract}

Christian Tudorache and Robyn A. O'Keefe contributed equally to this manuscript.

C. Tudorache $(\square)$

Institute of Biology, Leiden University, Sylviusweg 72,

2333 BE Leiden, The Netherlands

e-mail: c.tudorache@biology.leidenuniv.nl

R. A. O'Keefe · T. J. Benfey

Department of Biology, University of New Brunswick,

Fredericton, NB E3B 6E1, Canada swimming speed can be advantageous for the determination of swimming speeds for the use in aquaculture studies.

Keywords Swimming behaviour - Brook charr . Optimal swimming speed · Preferred swimming speed $\cdot$ Raceway $\cdot$ Respirometry

\section{Introduction}

A number of swimming performance levels have been described for fishes: sustained, prolonged and burst (Beamish 1978). Each swimming level has its own energetic characteristics, but sustained and prolonged swimming are mainly powered by red aerobic muscles while burst swimming is powered by white anaerobic muscles (Beamish 1978). Aerobically powered swimming modes are used for volitional routine swimming, important in activities such as migration, foraging, courtship, agonistic interactions. (Beamish 1978; Videler 1993). They also constitute the largest portion of a fish's energy budget (Brett 1964) and hence influence growth rates, energy available for reproductive effort, and in aquaculture, the amount of energy that can be transformed into fish meat. Such speeds are commonly small compared with the speed range of fishes and various measures of performance have been sought that pertain to such speeds. 
One such measure of performance at the low speed end of the spectrum at which volitional behaviour usually occurs is the optimal swimming speed defined at the speed at which the cost of transport (COT) is smallest (Tucker 1970). COT is in turn defined as the cost of moving unit mass over unit distance. Optimal swimming speed can be affected by various factors. Most commonly, $U_{\text {opt }}$ is based on rates of oxygen consumption, and hence is affected by temperature, fish size, endothermy and other factors influencing standard metabolic rate (Weihs 1973a; Beamish 1978; Webb 2006; Tudorache et al. 2007a). Weihs (1973a) has also shown that net energy gain can be used in considering $U_{\text {opt }}$, when slightly different values are obtained reflecting an ecological factor, food density.

Because $U_{\text {opt }}$ is a performance measure similar to speeds of fish during volitional activity, it has been used to evaluate the economics of routine activities and migration (e.g. Hinch and Rand 2000; Tudorache et al. 2007a; Palstra et al. 2008), behaviour maximizing net energy gain (Weihs 1973b) and hence is important in aquaculture in affecting growth for a given food intake (e.g. Totland et al. 1987; Christiansen et al. 1985; Davison 1997; Palstra et al. in prep.).

Several other measures of swimming performance are in common use, such as the critical swimming speed, $U_{\text {crit }}$, determined by forced-swimming increasing velocity tests (Brett 1964). However, there are both methodological difficulties in determining $U_{\text {crit }}$ (e.g. Tudorache et al. 2007b; Peake and Farrell 2004) and conceptual uncertainties because of behavioural parameters that influence the results (Farrell 2007). The defining characteristic of speeds used in routine activities is, of course, that they are volitional, and hence, fish can choose the speed at which they swim. This leads to the concept that there are preferred speeds, $U_{\text {pref }}$, for fishes. For example, fishes in lotic situations typically choose locations within a small speed range and in lentic situations, swim for most of the time within a similar small speed range. $U_{\text {pref }}$ is therefore a direct measure of performance relevant to behaviours central to fish ecology, and hence also to human-managed systems.

Therefore, we explored the use of $U_{\text {pref }}$ as a volitional swimming speed, using a tilted raceway setup with gradually increasing upstream water speed to determine $U_{\text {pref }}$ in a repeatable fashion (Peake and
Farrell 2004). We also compared $U_{\text {pref }}$ with $U_{\text {opt }}$ calculated from metabolic rate measured during forced-swimming tests in a Blazka-type respirometer.

\section{Materials and methods}

Fish

Brook charr $\left(26.2 \pm 0.6 \mathrm{~cm}\right.$, total length, $L_{T}$, mean \pm $\mathrm{SD}, N=10$ ) were caught by means of angling with a barbless hook from a private fish pond (Nashwaak Village, New Brunswick, Canada). Upon transport to the aquaculture facilities at the University of New Brunswick (Fredericton campus, Fredericton, New Brunswick, Canada), they were kept in dechlorinated municipal water for 7-15 days prior to experimentation at $12.2^{\circ} \mathrm{C}$ (range $\pm 0.9^{\circ} \mathrm{C}$ ) at a low current speed in the tanks $\left(0-10 \mathrm{~cm} \mathrm{~s}^{-1}\right)$. Fish were fed a salmonid grower diet (Corey Feed Mills Ltd., Fredericton, NB, Canada) ad libitum. Fish fed and behaved naturally in captivity. The experiments were conducted between July and August, 2008.

Ten fish were used in both $U_{\text {pref }}$ and $U_{\text {opt }}$ trials. For five fish, $U_{\text {pref }}$ was measured first followed by $U_{\text {opt }}$, and for the remainder, $U_{\text {opt }}$ was determined before transfer to the tilted flume to determine $U_{\text {pref. After a }}$ fish had completed both tests, each fish was anaesthetized in a $1 \%$ solution of tertiary amyl alcohol. Body mass and total length $L_{T}$ were measured, averaging $200 \pm 13 \mathrm{~g}$ and $26.2 \pm 0.6 \mathrm{~cm}$, respectively (mean $\pm \mathrm{SD}$ ).

Preferred swimming speed $\left(U_{\text {pref }}\right)$

$U_{\text {pref }}$ was determined in a Plexiglas raceway with gradually increasing water speed due to a $3.5^{\circ}$ inclination (Fig. 1, see also Tudorache et al. 2010 for details). The raceway was $450 \mathrm{~cm}$ long, $12.5 \mathrm{~cm}$ wide and $50 \mathrm{~cm}$ deep. The $3.5^{\circ}$ inclination resulted in an upstream water depth of $5 \mathrm{~cm}$ and water speed of $110 \mathrm{~cm} \mathrm{~s}^{-1}$ and a downstream water depth of $40 \mathrm{~cm}$ and speed of $10 \mathrm{~cm} \mathrm{~s}^{-1}$. Water speed was measured every $10 \mathrm{~cm}$ (flow probe HFA-U276, Hoentzsch $\mathrm{GmbH}$, Weiblingen, Germany) and showed a steady decrease towards the downstream end of the raceway. With the exception of the upstream $40 \mathrm{~cm}$ of the raceway, the water stream was free of turbulences, according to a dye test, which was performed by 


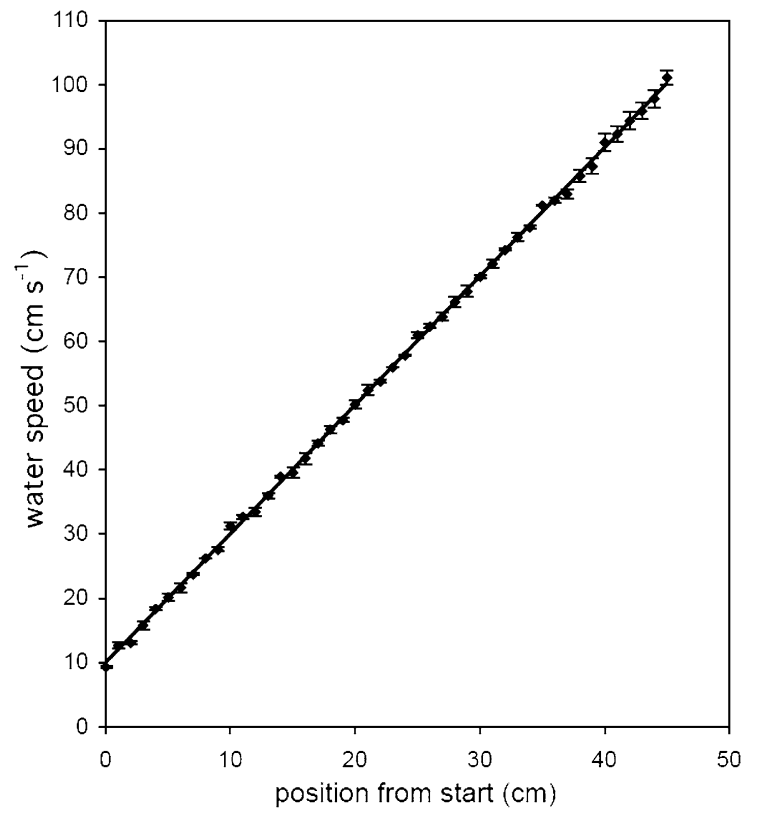

Fig. 1 Water velocities at positions from start of flume (mean $\pm \mathrm{SD}, N=3$ )

dripping a few drops of ink in the water, and the turbulences noted in the upper $40 \mathrm{~cm}$ were minimal. The downstream end was fitted with a holding tank, $75 \mathrm{~cm}$ long, $50 \mathrm{~cm}$ wide and $50 \mathrm{~cm}$ deep (Fig. 2). Water was pumped from the downstream tank to the upstream end of the flume by means of a submersible pump (Alita Model PV-800; Aracadia, CA, USA). The total volume of water was 2501 . Water temperature was maintained at $15^{\circ} \mathrm{C}$ with an in-line chiller (Aqua Logic Model DS-7; San Diego, CA, USA) and dissolved oxygen concentration did not fall below $7.5 \mathrm{mg} \mathrm{l}^{-1}$. Eight cameras (SNG SED-CAM-YC26S, Sharpe Electronics Corp., Osaka, Japan), connected to a digital video recorder (EDVR 16 D3, Everfocus, Taipei, Taiwan, see Tudorache et al. 2010 for comparison), were mounted ca $1 \mathrm{~m}$ below the

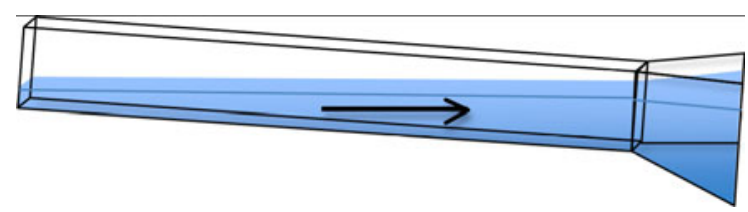

Fig. 2 Schematic three-dimensional drawing of the tilted raceway with downstream holding tank. The arrow indicates direction of the water flow raceway so they could record images of a section of $70 \mathrm{~cm}$ with overlapping fields. A grid on the bottom over the entire length of the raceway facilitated orientation and scaling.

Fish were introduced to the downstream holding tank at the low velocity end of the raceway $16 \mathrm{~h}$ before the experiment. Access to the raceway was blocked with a grid. After the acclimation period, the grid was removed and fish locations and behaviour were recorded for the following $4 \mathrm{~h}$. At the end of the experiment, fish were gently removed from the raceway by means of netting (hand net, $30 \times 15 \times$ $15 \mathrm{~cm}$ ) for recovery prior to measuring $U_{\text {opt }}$ or for mass and length measurement.

Video footage in mp4 format (25 fps) was analysed using the program ImageViewer (Everfocus, Taipei, Taiwan). Locations of the centre of mass (determined according to Tudorache et al. 2008) of each fish were recorded along the raceway. Swimming speeds (i.e. position holding against water speeds) were categorized in intervals of $5 \mathrm{~cm} \mathrm{~s}^{-1}$ and indicated as $U \pm 2.5 \mathrm{~cm} \mathrm{~s}^{-1}$, so that, for example, all speeds between 7.75 and $12.25 \mathrm{~cm} \mathrm{~s}^{-1}$ were categorized as $10 \mathrm{~cm} \mathrm{~s}^{-1}$, between 12.5 and 17.5 as $15 \mathrm{~cm} \mathrm{~s}^{-1}$, etc. If a fish spent more than $3 \mathrm{~s}$ within an interval, then it was defined as being swimming at a 'steady' speed. Shorter durations or variable ground speeds were defined as 'transient' associated with fishes changing location along the raceway. These observations resulted in time (min) spent swimming at specific current speed intervals.

The choice for $3 \mathrm{~s}$ as a threshold between steady and transient swimming behaviour is arbitrary. A different time interval would lead to different proportions of total time spent in steady and transient swimming. However, the distributions of time spent at different speeds would be resulting in similar values for $U_{\text {pref. }}$.

Optimal swimming speed $\left(U_{\text {opt }}\right)$

A 351 Blazka-type respirometer (as described by Kutty and Saunders 1973) was used to determine $U_{\text {opt }}$. The inner tunnel $(108 \mathrm{~cm}$ length $\times 12.8 \mathrm{~cm}$ diameter $)$ served as a swim chamber in which the fish were contained by means of screens located at either end. Oxygen concentration of the water was measured with a probe (Oxyguard Standard Probe, Oxyguard 
International $\mathrm{A} / \mathrm{S}$, Brikerød, Denmark) that was inserted in the outer tunnel connected to a data collecting system (Oxyguard Multichannel System) and data-logger system (Oxyguard Multilog) connected to a PC. Data were collected with Windows Hyperterminal.

Fish were allowed $2 \mathrm{~h}$ acclimation in oxygensaturated $\left(>10 \mathrm{mg} \mathrm{l}^{-1}\right)$ flow-through water at $10 \mathrm{~cm} \mathrm{~s}^{-1}$ at $15^{\circ} \mathrm{C}$ after transfer into the inner tunnel. An acclimation of $2 \mathrm{~h}$ is sufficient for repeatable performance measures in increasing velocity trials (Farrell et al. 1998; Jain and Farrell 2003). After acclimation, oxygen consumption was measured from changes in dissolved oxygen levels over 20-min period when water throughput was turned off followed a 30-min period flushing period to replace the oxygen used. Oxygen levels never dropped below $7.5 \mathrm{mg} \mathrm{l}^{-1}$. Oxygen consumption was measured at current speeds of $10,20,30,40$ and $50 \mathrm{~cm} \mathrm{~s}^{-1}$ imposed in random order to avoid a possible habituation effect on the results. However, direct observation of the fish in the swimming tunnel revealed an unstable swimming behaviour, characterized by deployment of pectoral fins, irregular position holding and exploring the tunnel, at $10 \mathrm{~cm} \mathrm{~s}^{-1}$, therefore the $\dot{M} \mathrm{O}_{2}$ data at $10 \mathrm{~cm} \mathrm{~s}^{-1}$ were not taken into account.

Various models have been used to describe the relationship between metabolic rate and swimming speed: linear, power and exponential (Webb 1997). Equations using various models were explored and that with largest $r^{2}$ was selected as that with the best fit. This was a polynomial function for these data: $\left(r^{2}=1\right)$

$\dot{M} \mathrm{O}_{2}=a U^{3}-b U^{2}-c U+\mathrm{SMR}$,

where $\dot{M} \mathrm{O}_{2}$ is oxygen consumption rate $\left(\mathrm{mg} \mathrm{g}^{-1} \mathrm{~h}^{-1}\right)$, SMR is standard metabolic rate $\left(\mathrm{mg} \mathrm{g}^{-1} \mathrm{~h}^{-1}\right)$ and determined by extrapolating the curve to zero swimming speed (Tudorache et al. 2007a), $U$ is swimming speed $\left(\mathrm{cm} \mathrm{s}^{-1}\right)$ and $a, b$ and $c$ are constants.

COT was determined by dividing $\dot{M} \mathrm{O}_{2}$ values by the swimming speed. The $U_{\text {opt }}\left(\mathrm{m} \mathrm{s}^{-1}\right.$ and $\left.\mathrm{bl} \mathrm{s}^{-1}\right)$, where the COT $\left(\mathrm{mg} \mathrm{O}_{2} \mathrm{~kg}^{-1} \mathrm{~m}^{-1}\right)$ reached a minimum (Tucker 1970), was determined by plotting the polynomial trend line through COT values versus swimming speeds per individual fish. The point on this trend line with the lowest COT $\left(\mathrm{COT}_{\min }\right)$ was calculated by setting the first derivative to zero (Palstra et al. 2008).

\section{Statistics}

Normality of the data used for analysis was determined by Kolmogorov-Smirnov tests. $U_{\text {pref }}$ data $>5 \%$ steady swimming time were compared with each other using one-way ANOVA $(P<0.05) . U_{\text {opt }}$ and $U_{\text {pref }}$ were compared with each other using the non-parametric Wilcoxon matched pairs test with a significance level of 0.05 . Results are as means \pm standard deviation (SD).

\section{Results}

Preferred swimming speed $\left(U_{\text {pref }}\right)$

After opening the grid, fish spent about $10 \mathrm{~min}$ in the holding tank before entering the raceway. All fish tested entered the raceway eventually spontaneously, without external motivation. Then, the fish spent about 20-30 min exploring the raceway, especially upstream, and below the upstream water entrance where water flow was turbulent.

Fish spent $178.0 \pm 12.1$ min (mean \pm SD; $73.6 \pm$ $4.4 \%$ of the total time) at a steady speed and $63.6 \pm 10.2 \mathrm{~min}(26.3 \pm 4.4 \%$ of the time $)$ transitioning from steady swimming at various locations. Most time was spent at swimming speeds of the speed category of $20 \mathrm{~cm} \mathrm{~s}^{-1}\left(0.78 \pm 0.02 \mathrm{bl} \mathrm{s}^{-1}\right)$ and $25 \mathrm{~cm} \mathrm{~s}^{-1}\left(0.97 \pm 0.02 \mathrm{bl} \mathrm{s}^{-1}\right.$; each representing approximately $25 \%$ of the steady speed time, statistically not different, one-way ANOVA, $P>0.05$ ), followed by $15 \mathrm{~cm} \mathrm{~s}^{-1}(10 \%)$ and $30 \mathrm{~cm} \mathrm{~s}^{-1}(5 \%)$ (Fig. 3). Fish did not swim at other speeds for more than $5 \%$ of the time spent in steady swimming; therefore, those data were not considered for analysis.

Optimal swimming speed $\left(U_{\text {opt }}\right)$

After introduction in the respirometer, swimming at speeds of $10 \mathrm{~cm} \mathrm{~s}^{-1}$, swimming was not steady for the entire period of swimming at $10 \mathrm{~cm} \mathrm{~s}^{-1}$ during which fish explored the respirometer. Only at a swimming speed of $20 \mathrm{~cm} \mathrm{~s}^{-1}$ did swimming behaviour become steady. 


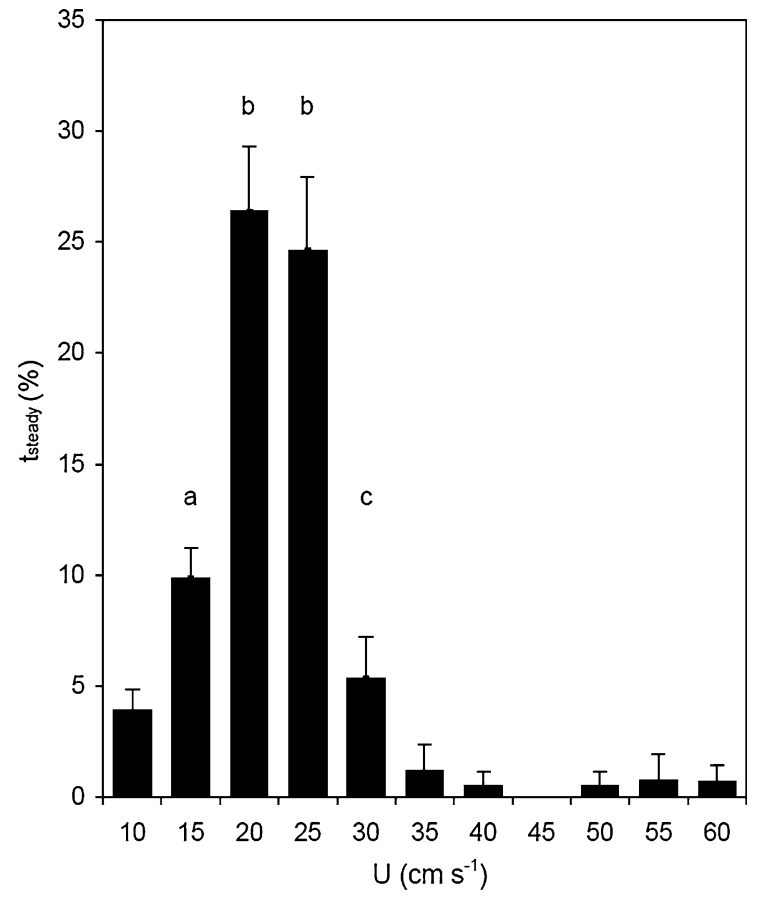

Fig. 3 The time (\% total steady swimming time) spent swimming steadily plotted against clusters of swimming speeds of $5 \mathrm{~cm} \mathrm{~s}^{-1}$ (see text for details). Letters indicate significant differences between values $>5 \%$ of total steady time (one-way ANOVA, $P<0.05$ )

Figure 4 shows $\dot{M} \mathrm{O}_{2}$ values plotted polynomially against swimming speeds. The best-fit equation revealing $\dot{M} \mathrm{O}_{2}$ to $U$ was the following: $\dot{M} \mathrm{O}_{2}=$ $-0.0104 U^{3}+1.010 U^{2}-18.671 U+258.81 \quad\left(r^{2}=\right.$ $1 ; P<0.05) . \mathrm{COT}_{\min }$ at a $U_{\mathrm{opt}}$ averaged $25.9 \pm$ $8.9 \mathrm{~cm} \mathrm{~s}^{-1}\left(1.01 \pm 0.35 \mathrm{bl} \mathrm{s}^{-1}\right)$ is $0.97 \pm 0.06$ $\mathrm{mg} \mathrm{g}^{-1} \mathrm{~m}^{-1}$.

When comparing $U_{\text {opt }}$ with the $U_{\text {pref }}$ categories with the highest time values, i.e., 20 and $25 \mathrm{~cm} \mathrm{~s}^{-1}$, Wilcoxon matched pairs test revealed a significant difference between $U_{\text {opt }}$ and $U_{\text {pref }}$ of $20 \mathrm{~cm} \mathrm{~s}^{-1}$ $(P<0.05)$ but no difference between $U_{\text {opt }}$ and $U_{\text {pref }}$ of the speed category of $25 \mathrm{~cm} \mathrm{~s}^{-1}(P>0.05)$.

\section{Discussion}

This study sought to evaluate the utility of measuring preferred swimming speeds ( $U_{\text {pref }}$ ) in comparison with the more common reference of optimal swimming speed $\left(U_{\text {opt }}\right)$ for low-speed behaviours. $U_{\text {pref }}$

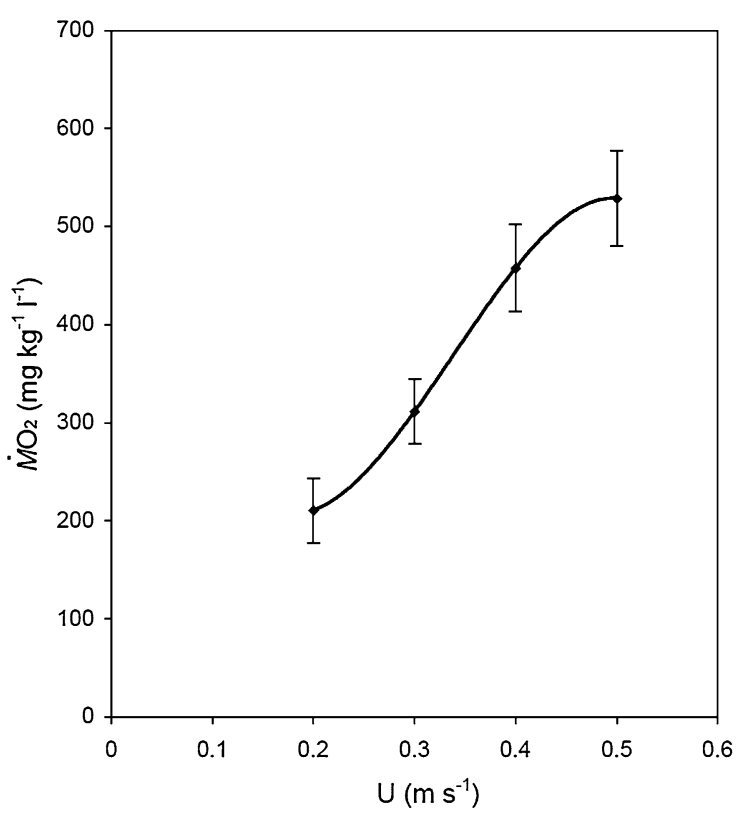

Fig. 4 Relative oxygen consumption $\left(\dot{M} \mathrm{O}_{2}\right)$ plotted against swimming speed of brook charr swimming in a confined respirometer. The fitting curve is provided by the polynomial function $\dot{M} \mathrm{O}_{2}=-0.0105 U^{3}+1.006 U^{2}-18.665 U+\mathrm{SMR}$ $\left(r^{2}=0.99, N=10\right)$ with $U$ being swimming speed $\left(\mathrm{cm} \mathrm{s}^{-1}\right)$ and SMR, the standard metabolic rate, has a value of $258.77 \mathrm{mg} \mathrm{O}_{2} \mathrm{~kg}^{-1} \mathrm{l}^{-1}$

chosen volitionally by fasted trout in the current speed gradient of the raceway was reflected by $U_{\text {opt }}$ determined from metabolic rates measured during forced-swimming in a flume, which was within the range of $U_{\mathrm{opt}}$ found in salmonids of 10-29 cm body length at $15^{\circ} \mathrm{C}$ water temperature, i.e., $U_{\text {opt }}$ of $1-2$ body lengths $\mathrm{s}^{-1}$ (Brett 1964; Webb 1971a, b). Additionally, in aquaculture, growth for various salmonids is maximized at a constant swimming speed of $1.5 \mathrm{bl} \mathrm{s}^{-1}$ (Davison and Goldspink 1977; Jørgensen and Jobling 1993). Also, spontaneous activity data from migration and aquaculture studies at similar water temperatures and size classes suggest a range of speeds from 0.5 to $3 \mathrm{bl} \mathrm{s}^{-1}$ (Cooke et al. 2000; Thorstad et al. 2004; Babaluk et al. 2001). This indicates that the calculated $U_{\text {opt }}$ is not necessarily the only speed at which fish migrate (Standen et al. 2002) or swim in aquaculture facilities (Cooke et al. 2000).

The time spent swimming steadily is strongly skewed to lower speeds between 10 and $40 \mathrm{~cm} \mathrm{~s}^{-1}$. The skew arises from a small cluster of speeds between 50 and $60 \mathrm{~cm} \mathrm{~s}^{-1}$ which in practice represents less than $5 \%$ of the total time spent swimming 
steadily. These speeds occurred primarily after fish first entered and explored the flume when initially they tended to explore the upstream end of the system. This was the area where flow tended to be more turbulent as noted during dye tests. The fish may have been attempting to use the energy in the eddies that comprise turbulence (Breder 1965; Webb 1998; Lupandin 2005), but found the scale was not well matched to their size (Webb et al. 2010; Webb and Cotel 2010). Thus, these observations were considered qualitatively different from those after the initial exploration and were excluded from the analysis. The resulting time intervals spent swimming steadily at various speeds were then normally distributed.

It can be objected that fish chose a specific location along the raceway not for the water speeds encountered but for the water depths. Unpublished observations during a pilot study to another published research using the same set-up (Tudorache et al. 2010) revealed that smaller brook charr (ca. $12 \mathrm{~cm}$ $L_{T}$ ) were showing the same behaviour of settling at a certain swimming speed after exploring the raceway. When altering the water discharge of the pump and therefore the water speeds at different locations along the raceway, fish chose similar speeds, independent of water depth, which remained always the same due to the inclination of the raceway. This observation gave the original idea to the present study. Therefore, it is unlikely that the specific position along the raceway was chosen for its water depth.

The results show that for the determination of $U_{\mathrm{opt}}$ speeds below $20 \mathrm{~cm} \mathrm{~s}^{-1}$ could not be used due to unsteady swimming behaviour of the fish. Direct observation of the swimming behaviour at such low speeds suggested that velocities were too low to be held in steady swimming mode, and the fish was confined in too small space to fully express volitional swimming behaviour. The described erroneous swimming behaviour, involving deployment of pectoral fins, irregular position holding etc., can be interpreted as a reaction to this situation. Therefore, the usefulness of $U_{\text {opt }}$, conceptually an ecologically important reference speed, is diminished because of the low sensitivity to speeds in the range seen during routine activity, foraging and migration. Linear swimming at such low speeds in limited space can be obstructed by their own unsteady nature and reduce the reliability of the results. Alternatively, $U_{\text {pref }}$, as measured in the present study, is based on volitional swimming behaviour at a variety of velocities. Also, space is not a restrictive factor. Hence, $U_{\text {pref }}$ may be a preferable measure for swimming speeds in the field and aquaculture facilities. However, the method applied in the present study reveals a very broad result of $U_{\text {pref }}$, i.e., a value spanning from 17.5 to $27.5 \mathrm{~cm} \mathrm{~s}^{-1}$ as the speed categories of 20 and $25 \mathrm{~cm} \mathrm{~s}^{-1}$ are approximations $\pm 2.5 \mathrm{~cm} \mathrm{~s}^{-1}$. A more accurate result could be obtained using next to the present set-up an automated cine installation, similar to the one used by Tudorache et al. (2009), where swimming speeds and resting times/positions can be detected automatically. This could facilitate the process of data collection and make the resulting $U_{\text {pref }}$ more accurate.

There is growing awareness among that forcedswimming tests are influenced by fish behaviour (see Farrell 2007, for a review). For example, Peake and Farrell (2004) showed that swimming smallmouth bass (Micropterus dolomieu; $24-38 \mathrm{~cm}$ fork length) reach a much higher gait transition speed $\left(U_{\mathrm{gt}}\right)$ when swimming freely up a $50 \mathrm{~m}$ long raceway compared with $U_{\text {crit }}$ values obtained from a forced swim tunnel experiment. Similarly, Tudorache et al. (2007b) showed that $U_{\text {crit }}$ of common carp (Cyprinus carpio; $5-26 \mathrm{~cm}$ standard length) in swimming tunnels is influenced by tunnel length. Taken together, these data indicate that tests of performance with fewer constraints on behaviour provide results more relevant to understanding fish biology, and applying results to managed systems such as in aquaculture. Given the recognized relationship between exercise and optimum growth and condition in cultured fish, whether for stocking programs or meat production (Davison 1997; McDonald et al. 1998), the results of this study suggest a biomechanical and behavioural basis contributing at least in part to for these observations.

\section{Perspectives}

Rearing aquaculture fish under exercise conditions improves growth and food conversion efficiencies and thus leads to better economic returns (Davison 1997). It enhances muscle growth (Davison and Goldspink 1977; Johnston and Moon 1980; Totland et al. 1987) and flesh quality (Totland et al. 1987; Tsuchimoto et al. 1988), reduces aggressive 
interactions between fish (Adams et al. 1995; Christiansen and Jobling 1990; Christiansen et al. 1991, 1992; East and Magnan 1987; Jobling et al. 1993) and leads to a reduction in stress response (Woodward and Smith 1985; Young and Cech 1993, 1994). It is advisable to keep water speeds applied in aquaculture facilities near $U_{\mathrm{opt}}$, as $U_{\mathrm{opt}}$ is the swimming speed with the lowest COT (Videler 1993). However, there is no indication, yet, that fish given the choice between swimming speeds would volitionally chose for swimming velocities near $U_{\text {opt }}$, the $U_{\text {pref }}$, a fact that is confirmed by the present study.

Volitional swimming tests have been shown to be a good alternative to forced-swimming tests, due to the effect of the forced character on the results (see Farrell 2007 for a review). The present study presents an alternative measurement of $U_{\text {opt }}$, merely based on behavioural observation. It is less invasive as traditional $U_{\text {opt }}$ tests and based on volitional swimming instead of the traditional forced-swimming tests. This volitional swimming test can be used to compare different species, strains, size classes or ploidies, in order to find perfect rearing conditions for aquaculture fish. Also, it can be argued biomechanically that different muscle types have different optimal swimming speeds for growth (Davison 1997). Therefore, it would be advantageous to present cultured fish with the opportunity of choosing between different water speeds. During the present study, fish in the raceway chose one speed interval at which they remained steady, for the longest period during the observation time of $6 \mathrm{~h}$. However, this is only a short-time window, and it is possible that other speeds would have been chosen, depending on the time of the day, feeding regime, rearing density and other factors typical for an aquaculture environment. Additionally, it has been shown by Weihs (1973a) that $U_{\text {opt }}$, measured in a traditional way using forced-swimming tests, depends strongly on physiological and environmental conditions, and in the recent past behavioural, factors are increasingly made responsible for physiological parameters of fish swimming (Farrell 2007).

When building aquaculture facilities, a variation of water velocities can be presented for fish to choose. Possibly, a tilted rearing tank can be considered, based on the design of the flume in the present study. Different positions with similar water velocities, including dead zones, turbulent zones and high velocity zones within these tanks can help to reduce agonistic behaviour and lead to a more efficient and less stressful rearing situation for aquaculture fish. The results can be a significant increase in flesh quality and therefore economically interesting.

In conclusion, this study presents a new, volitional-based swimming speed, the preferred swimming speed, which should be explored in more detail in future studies and which can be taken into account for the improvement of aquaculture applications.

Acknowledgments Many thanks are extended to P. W. Webb for his invaluable help on the manuscript. S. J. Peake is acknowledged for his contributions to this research. The use of animals was approved by the UNB Animal Care Committee, following guidelines established by the Canadian Council on Animal Care. This research was partially supported by an NSERC Discovery Grant awarded to T. J. Benfey. C. Tudorache was supported by a grant from Manitoba Hydro awarded to S. J. Peake (Grant number: G215).

Open Access This article is distributed under the terms of the Creative Commons Attribution Noncommercial License which permits any noncommercial use, distribution, and reproduction in any medium, provided the original author(s) and source are credited.

\section{References}

Adams CE, Huntingford FA, Krpal J, Jobling M, Burnett SJ (1995) Exercise, agonistic behaviour and food acquisition in Arctic charr, Salvelinus alpinus. Env Biol Fish 43:213-218

Babaluk JA, Wissink HR, Troke BG, Clark DA, Johnson JD (2001) Summer movements of radio-tagged Arctic charr (Salvelinus alpinus) in Lake Hazen, Nunavut, Canada. Arctic 54(4):418-424

Beamish FWH (1978) Swimming capacity. In: Hoar WS, Randall DJ (eds) Fish physiology, vol 7, 1st edn. Academic Press, London, pp 101-187

Breder CM (1965) Vortices and fish schools. Zoologica 50:97-114

Brett JR (1964) The respiratory metabolism and swimming performance of young sockeye salmon. J Fish REs Bd Can 21:1183-1226

Christiansen JS, Jobling M (1990) The behaviour and the relationship between food intake and growth of juvenile Arctic charr, Salvelinus alpinus L., subjected to sustained exercise. Can J Zool 68:2185-2191

Christiansen DC, Skarstein L, Klungsøyr L (1985) Uptake studies in adipocytes isolated from rainbow trout (Salmo gairdneri). A comparison with adipocytes from rat and cat. Comp Biochem Physiol 82A:201-205

Christiansen JS, Jørgensen EH, Jobling M (1991) Oxygen consumption in relation to sustained exercise and social stress in Arctic charr (Salvelinus alpinus L.). J Exp Zool 260:149-156 
Christiansen JS, Svendsen YS, Jobling M (1992) The combined effects of stocking density and sustained exercise on the behavior, food intake, and growth of juvenile Arctic charr (Salvelinus alpinus L.). Can J Zool 70:115-122

Cooke SJ, Chandroo KP, Beddow TA, Moccia RD, McKinley RS (2000) Swimming activity and energetic expenditure of captive rainbow trout Oncorhynchus mykiss (Walbaum) estimated by electromyogram telemetry. Aquacult Res 31:495-505

Davison W (1997) The effects of exercise training on teleost fish, a review of recent literature. Comp Biochem Physiol A 117(1):67-75

Davison W, Goldspink G (1977) The effect of prolonged exercise on the lateral musculature of the brown trout Salmo trutta. J Exp Biol 70:1-12

East P, Magnan P (1987) The effect of locomotor activity on the growth of brook charr, Salvelinus fontinalis Mitchill. Can J Zool 65:843-846

Farrell AP (2007) Cardiorespiratory performance during prolonged swimming tests with salmonids: a perspective on temperature effects and potential analytical pitfalls. Phil Trans Royal Soc B 362:2017-2030

Farrell AP, Gamperl AK, Birtwell IK (1998) Prolonged Swimming, recovery and repeat swimming performance of mature Sockeye Salmon Oncorhynchus Nerka exposed to moderate hypoxia and pentachlorophenol. J Exp Biol 201:2183-2193

Hinch SG, Rand PS (2000) Optimal swimming speeds and forward-assisted propulsion: energy-conserving behaviours of upriver-migrating adult salmon. Can J Fish Aquat Sci 57:2470-2478

Jain KE, Farrell AP (2003) Influence of seasonal temperature on the repeat swimming performance of rainbow trout Oncorhynchus mykiss. J Exp Biol 206:3569-3579

Jobling M, Jørgensen EH, Arnesen AM, Ring $\varnothing$ E (1993) Feeding, growth and environmental aquirements of Arctic charr: a review of aquaculture potential. Aquaculture Int $1: 20-46$

Johnston IA, Moon TW (1980) Exercise training in skeletal muscle of brook trout (Salvelinus fontinalis). J Exp Biol 87:177-194

Jørgensen EH, Jobling M (1993) The effect of exercise on growth, food utilisation and osmoregulatory capacity of juvenile Atlantic salmon (Salmo salar). Aquaculture 116:233-246

Kutty MN, Saunders RL (1973) Swimming performance of young Atlantic salmon (Salmo salar) as affected by reduced ambient oxygen concentration. J Fish Res Board Can 30(2):223-227

McDonald DG, Milligan CL, McFarlane WJ, Croke S, Currie S, Hooke B, Angus RB, Tufts BL, Davidson K (1998) Condition and performance of juvenile Atlantic salmon (Salmo salar): effects of rearing practices on hatchery fish and comparison with wild fish. Can J Fish Aquat Sci 55:1208-1219

Palstra A, van Ginneken V, van den Thillart G (2008) Cost of transport and optimal swimming speed in farmed and wild European silver eels (Anguilla anguilla). Comp Biochem Physiol 151A:37-44

Peake SJ, Farrell AP (2004) Locomotory behaviour and postexercise physiology in relation to swimming speed, gait transition and metabolism in free-swimming smallmouth bass (Micropterus dolomieu). J Exp Biol 207:1563-1575

Standen EM, Hinch SE, Healey MC, Farrell AP (2002) Energetic costs of migration through the Fraser River canyon, British Columbia, in adult pink (Oncorhynchus gorbuscha) and sockeye (Oncorhynchus nerka) salmon as assessed by EMG telemetry. Can J Fisheries Aquat Sci 59:1809-1818

Thorstad EB, Økland F, Finstadt B, Sivertsgard R, Bjørn PA, McKinley RS (2004) Migration speeds and orientation of Atlantic salmon and sea trout post-smolts in a Norwegian fjord system. Environ Biol Fishes 71:305-311

Totland GK, Kryvi H, Jødestøl KA, Christiansen EN, Tangeras A, Slinde E (1987) Growth and composition of the swimming muscle of adult Atlantic salmon (Salmo salar L.) during long-term sustained swimming. Aquaculture 66:299-313

Tsuchimoto M, Tanaka N, Uesugi Y, Misima T, Tachibana K, Yada S, Senta T, Yasuda M (1988) The influence of rearing water temperature on the relative thermostability of myofibrillar Ca2+-ATPase and on the lowering speed of freshness in carp. Nippon Suissan Gakkaishi 54:117124

Tucker VA (1970) Energetic cost of locomotion in animals. Comp Biochem Physiol 34:841-846

Tudorache C, Blust R, De Boeck G (2007a) Swimming capacity and energetics of migrating and non-migrating morphs of three-spined stickleback Gasterosteus aculeatus L. and their ecological implications. J Fish Biol 71:1448-1456

Tudorache C, Viaenen P, Blust R, De Boeck G (2007b) Longer flumes increase critical swimming speeds by increasing burst-glide swimming duration in carp Cyprinus carpio, L. J Fish Biol 71:1630-1638

Tudorache C, Blust R, De Boeck G (2008) Social interactions, predation behaviour and fast start performance are affected by ammonia exposure in brown trout (Salmo trutta L.). Aq Tox 90:145-153

Tudorache C, Jordan AD, Svendsen JC, Domenici P, De Boeck G, Steffensen JF (2009) Pectoral fin beat frequency predicts oxygen consumption during spontaneous activity in a labriform swimming fish (Embiotoca lateralis). Environ Biol Fish 84:121-127

Tudorache C, O'Keefe RA, Benfey TJ (2010) The effect of temperature and ammonia exposure on swimming performance of brook charr (Salvelinus fontinalis). Comp Biochem Physiol A 156:523-528

Videler JJ (1993) Fish swimming. Chapman and Hall, London Webb PW (1971a) The swimming energetics of trout: I Thrust and power output at cruising speeds. J Exp Biol 55:489-520

Webb PW (1971b) The swimming energetics of trout: II Oxygen consumption and swimming efficiency. J Exp Biol 55:521-540

Webb PW (1997) Swimming. In: Evans DH (ed) The physiology of fishes, 2nd edn. CRC Press, Boca Raton, pp 3-24

Webb PW (1998) Entrainment by river chub Nocomis micropogon and smallmouth bass Micropterus dolomieu on cylinders. J Exp Biol 200:2403-2412

Webb PW (2006) Stability and maneuverability. In: Shadwick RE, Lauder GV (eds) Fish physiology. Elsevier Press, San Diego, pp 281-332 
Webb PW, Cotel AJ (2010) Turbulence: does vorticity affect the structure and shape of body and fin propulsors? Integr Comp Biol 50:1-12

Webb PW, Cotel AJ, Meadows LA (2010) Waves and eddies: effects on fish behaviour and habitat distribution. In: Domenici P, Kapoor BG (eds) Fish locomotion: an ecoethological perspective. Science Publishers, Enfield, pp 1-39

Weihs D (1973a) Optimal fish cruising speed. Nature 245:48-50

Weihs D (1973b) Hydromechanics of fish schooling. Nature 241:290-291
Woodward JJ, Smith LS (1985) Exercise training and the stress response in rainbow trout Salmo gairdneri Richardson. J Fish Biol 26:435-447

Young PS, Cech JJ (1993) Improved growth, swimming performance, and muscular development in exercised-conditioned young-of-the-year striped bass (Morone saxatilis). Can J Fish Aquat Sci 50:703-707

Young PS, Cech JJ (1994) Optimum exercise conditioning velocity for growth, muscular development, and swimming performance in young-of-the-year striped bass (Morone saxatilis). Can J Fish Aquat Sci 51:1519-1527 